\title{
Gramsci e os Intelectuais de Direita no Brasil Contemporâneo
}

\section{Leonardo Seabra Puglia ${ }^{1}$}

Resumo

Intelectuais abertamente alinhados à direita do espectro político foram ganhando nos últimos anos cada vez mais espaço na esfera pública brasileira, assumindo protagonismo na imprensa, no mercado editorial e nas redes sociais. A análise dos argumentos de nomes como os de Olavo de Carvalho, Reinaldo Azevedo e Luiz Felipe Pondé, entre outros, revela, contudo, uma interpretação comum da história recente do Brasil que enxerga na pretensa influência hegemônica do pensador comunista Antonio Gramsci na intelectualidade nacional a explicação central para boa parte das mazelas que afligem o Brasil. O objetivo do artigo é através da análise das ideias, retóricas e ações desses atores políticos discutir a relevância de Gramsci, como lido por esses personagens, para a compreensão de como os intelectuais da direita brasileira contemporânea interpretam a realidade social e percebem sua própria inscrição na vida pública num momento histórico de polarização em que suas ideias vêm ganhando ressonância crescente na sociedade brasileira.

Palavras-chave: Nova Direita; Gramsci; Hegemonia; Intelectuais; Direita

\section{Gramsci and the Right-Wing Intellectuals in Contemporary Brazil}

\section{Abstract}

In the last decade, right-wing intellectuals have become increasingly relevant in the Brazilian public debate, performing main roles in the traditional press, in the editorial market and also in social media. But when analyzing arguments of names such as Olavo de Carvalho, Reinaldo Azevedo e Luiz Felipe Pondé a common interpretation of Brazilian contemporary History emerges. An interpretation that puts a possible hegemonic presence of the Italian communist thinker Antonio Gramsci in Brazilian cultural life as the main reason for most of the social and political problems in Brazil. This paper aims to investigate the ideas, the rhetoric and actions of this political actors in an effort to discuss the relevance of Gramsci - as he is understood by them - to comprehend how the contemporary Brazilian intellectuals interpret social reality and perceive their own inscription in public life in a historical moment of polarization in which their ideas have been sprawling through Brazilian society.

Keywords: Right-Wing; Brazilian Politics; Gramsci; Intellectuals; Hegemony

1 Doutorando em Ciências Sociais pela Pontifícia Universidade Católica do Rio de Janeiro (PUC-RJ). 


\section{Introdução}

Nos últimos anos, intelectuais abertamente identificados com o ideário de direita foram ganhando espaço crescente na esfera pública nacional, assumindo protagonismo não somente na imprensa tradicional, como também no mercado editorial e nas redes sociais, onde personagens como Reinaldo Azevedo, Luiz Felipe Pondé, Rodrigo Constantino e Olavo de Carvalho estabelecem diálogo diário com milhares de seguidores, incluindo número cada vez mais expressivo de jovens identificados com o pensamento conservador.

Ainda que a presença da intelectualidade de direita no cenário cultural, acadêmico e político brasileiro não seja propriamente uma novidade, e esse mesmo grupo heterogêneo analisado no presente artigo - que também inclui nomes como os de Marco Antonio Villa, Diogo Mainardi e Flávio Gordon, entre outros - acumule décadas de atuação profissional, é possível notar um fortalecimento crescente de sua influência na esfera pública brasileira a partir, sobretudo, dos anos 2000.

São personagens de perfis diversificados, mas que apesar das divergências internas - algumas marcadas por trocas de ofensas públicas -, aproximam-se num esforço comum de atualização das agendas tradicionais de direita, unindo conservadorismo moral e adesão ao capitalismo liberal na construção de narrativas que tendem a interpretar os fatos da política cotidiana apontando a esquerda como responsável direta pela maior parte das mazelas do país.

Um esforço de compreensão das dinâmicas que caracterizam um cenário político e social marcado por tensões e incertezas como as que vem enfrentando o Brasil nos últimos anos deve passar, portanto, por análise que busque ir além das possíveis preferências ideológicas do pesquisador, para identificar elementos capazes de iluminar as racionalidades por trás do fortalecimento da inserção desses intelectuais como atores políticos e da ressonância crescente que suas ideias e argumentos vêm encontrando na sociedade brasileira. Sendo um trabalho relevante nesse sentido A Nova Direita Brasileira: Ideias, Retórica e Prática Política, enquanto ponto de partida para o pesquisador que deseje se arriscar num caminho tornado especialmente espinhoso pela polarização radical e pela histeria generalizada que têm marcado o debate público sobre política e ideologia no Brasil desde as eleições presidenciais de 2014.

No artigo publicado em 2016 na revista Insight Inteligência, o cientista político Jorge Chaloub e o historiador Fernando Perlatto chamam atenção para a relevância do fenômeno, apontando pontos de aproximação e afastamento entre os argumentos dos mais influentes intelectuais de direita. Nessa abordagem exploratória, são apresentadas seis grandes hipóteses capazes de ajudar a compreender o destaque que esses atores sociais têm alcançado na cena cultural do país.

A primeira proposição é de que não se trata de fenômeno exclusivamente brasileiro, mas tendência internacional, identificada por Jürgen Habermas na Alemanha e nos Estados Unidos ainda nos anos 1980. Nesse sentido, as últimas décadas teriam sido marcadas pelo ressurgimento de vertentes variadas do pensamento de direita em diversas partes de mundo, impulsionadas - de maneira geral - pela crise do Estado de Bem-estar social e pelo abalo provocado no pensamento marxista pelo desmoronamento do Bloco Soviético.

No caso específico do Brasil, o distanciamento temporal da ditadura militar também estaria impulsionando o fenômeno, ao deixar setores sociais identificados com a direita mais à vontade para assumirem suas opiniões sem constrangimento, uma vez que o regime costuma ser identificado como "de direita" pela historiografia tradicional e pelo imaginário social.

Chaloub e Perlatto (2016) propõe ainda como hipóteses os impulsos de atores sociais liberais de reagir às políticas de redistribuição de renda dos governos petistas com propostas ancoradas na agenda do Estado mínimo, através da articulação 
de empresários, economistas, juristas, jornalistas e outros intelectuais em redes think tanks orientadas para a defesa dos valores e das políticas liberais. Sendo os institutos Millenium, Ordem Livre e Ludwig Von Misses exemplos ilustrativos nesse sentido.

Articulados nessas redes institucionais, ramificadas internacionalmente e patrocinadas por grandes grupos empresariais, os intelectuais da chamada "nova direita" estariam encontrando cada vez mais espaço também na mídia tradicional e no mercado editorial, além de terem se revelado especialmente hábeis no uso da internet - sobretudo de redes sociais como Twitter e Facebook - para explorar politicamente os erros do grande inimigo comum, o PT, ganhando espaço num momento de crise do sistema partidário que, de tão aguda, torna generalizado o clima de desconfiança em relação aos políticos e instituições.

Além de apresentarem hipóteses para a compreensão do fenômeno, Chaloub e Perlatto se debruçaram sobre alguns dos principais argumentos defendidos por esses intelectuais em suas intervenções públicas. E, entre os discursos constantes, ganha destaque o que atribui as mazelas, recentes e pregressas, do país a um suposto predomínio da esquerda no cenário político e intelectual. Predomínio que teria começado a se sedimentar ainda no fim da ditadura militar, tornando-se, nas últimas três décadas, hegemônico a ponto de sufocar vozes dissidentes - como as dos de direita intelectuais em questão -, sobretudo na academia, alvo de violentas críticas enquanto "antro de doutrinação esquerdista e devassidão moral, onde o que sobra são títulos, cursos e escritos tão inúteis quanto viciados" (CHALOUB e PERLATTO, 2016, p. 35).

Com a mídia, a vida acadêmica e cena cultural supostamente controladas pela esquerda - considerada, com seu relativismo, como moralmente inferior à direita - o resultado teria sido a disseminação generalizada de falsificações, vendidas como verdades, com objetivo de destruir valores caros à população brasileira conservadora, em sua ampla maioria, segundo tal linha de argumentação - e também de distorcer a história nacional em seu favor. Sendo o principal exemplo nesse sentido as leituras históricas hegemônicas sobre golpe de 1964 e a ditadura militar, que atribuiriam injustamente papel de vilão aos militares que salvaram o país da implantação iminente de uma ditadura comunista.

Longe de ser um denominador comum acidental, essa leitura particular da história recente do Brasil, compartilhada sem divergências significativas pelos intelectuais da "nova direita", é um elemento decisivo para compreender como esse grupo interpreta o país e percebe sua própria atuação como agentes históricos, vendose empurrados pelo dever moral a combater o mesmo inimigo, o PT, partido que seria o vértice e ponto de articulação do processo de crescente domínio da esquerda na vida política e intelectual nacional. Processo que, segundo tal interpretação, levaria, necessariamente, à implantação definitiva do totalitarismo comunista do Brasil.

Desqualificada por parte significativa da intelectualidade de esquerda ao longo dos anos, tal narrativa foi ganhando espaço, sobretudo entre as camadas médias, desempenhando papel decisivo na eleição de Jair Bolsonaro a Presidência da República em 2018.

O presente artigo parte da hipótese de que, entre os fatores que levaram ao sucesso do campo conservador nas ruas e nas urnas, está o fortalecimento da influência desses novos intelectuais de direita na esfera pública nacional. Daí a proposta de dar continuidade ao esforço de interpretação de ideias, retórica e prática política dos intelectuais da "nova direita" brasileira, tomando essa narrativa comum acerca da histórica recente do país como ponto de partida.

Não foi preciso muito tempo, contudo, para que saltasse à vista durante a leitura dos textos e a análise das intervenções públicas desses intelectuais em diferentes mídias - foram esses os métodos de coleta de dados adotados neste artigo - a presença constante, ainda que fantasmagórica, de um "personagem que nunca esteve aqui, do qual a maioria dos brasileiros nunca ouviu falar, e que ademais está morto há mais de meio século, 
mas que, desde o reino das sombras, dirige em segredo os acontecimentos nesta parte do mundo" e sem o qual seria impossível "reduzir a um quadro coerente o aglomerado caótico de elementos que se agitam na cena brasileira”, para adotar palavras do próprio Olavo de Carvalho (1994, p. 46).

Já em 1994, Olavo afirmava que esse processo de hegemonia crescente da esquerda no plano intelectual e cultural iniciado na década de 1970 tinha origem na "conversão formal ou informal, consciente ou inconsciente da intelectualidade de esquerda à estratégia de Antonio Gramsci", evidência que seria na sua opinião, "o fato mais relevante da História nacional dos últimos trinta anos" (CARVALHO, 1994, p. 15).

\section{Gramsci e a hegemonia da esquerda no Brasil}

Quando apresentada no livro A Nova Era e a Revolução Cultural: Fritjof Capra \& Antonio Gramsci (1994), a tese foi recebida com desconfiança, diante de um mundo em que a utopia socialista parecia definitivamente derrotada pelo desmoronamento do Bloco Soviético. O argumento, todavia, acabaria se fortalecendo com o passar do tempo, disseminando-se com maior força, sobretudo, a partir da eleição de Lula, em 2002.

"Num momento em que ninguém se reivindicava como direita, ele foi um cavaleiro solitário, e essa pregação no deserto rendeu grandes frutos", afirma o pesquisador Pablo Ortellado sobre o intelectual que seria, na sua opinião, uma espécie de "pai espiritual da nova direita" (BBC, 2016), tese que seria reforçada pela influência de Olavo na formação do ministério de Bolsonaro.

A análise dos textos e das intervenções públicas de outros intelectuais relevantes do grupo revela, contudo, que longe de ser uma visão pessoal de Olavo, a tese que atribui a pretensa hegemonia da esquerda no mundo intelectual brasileiro à difusão do pensamento de Antonio Gramsci é, na verdade, consenso entre nomes como Rodrigo Constantino, Reinaldo Azevedo e Luiz Felipe Pondé. O primeiro, por exemplo, reiterou o argumento em diversos artigos, recuperando-o no capítulo sobre 'O Viés da Imprensa' do livro Esquerda Caviar: a Hipocrisia dos Artistas e Intelectuais Progressistas no Brasil e no Mundo (2013), enquanto os dois últimos tiveram oportunidade de denunciar a onipresença de Gramsci na cultura brasileira na TV, durante entrevista concedida a William Waack em edição do programa Painel sobre "direita e esquerda", exibida pelo canal por assinatura GloboNews em dezembro de 2012.

No caso específico de Olavo de Carvalho, considerado como pioneiro e formulador dos principais argumentos defendidos pelos intelectuais de direita na atualidade, a presença de Gramsci em seu trabalho é inquestionável. O nome do comunista sardo aparece nada menos que 318 vezes se somarmos as quatro obras mais influentes publicadas pelo autor que diz ter aberto espaço para o surgimento dessa nova direita no país (BBC, 2016): O Jardim das Aflições: de Epicuro à Ressurreição de César - Ensaio Sobre o Materialismo e a Religião Civil (1998); O Mínimo que Você Precisa Saber para não Ser um Idiota (2013); O Imbecil Coletivo: Atualidades Inculturais Brasileiras (1996); e A Nova Era e a Revolução Cultural: Fritjof Capra \& Antonio Gramsci (1994). Fazendo os dois últimos livros referência a Gramsci no próprio título, uma vez que Olavo cunha o termo "imbecil coletivo" como ataque declarado - em defesa do pensamento individual como única fonte verdadeira de conhecimento - ao elogio do intelectual coletivo proposto pelo conceito do "moderno príncipe" gramsciano (GRAMSCI, 2012):

\footnotetext{
"É de massas de jovens pseudoletrados que se compõe, precisamente, o 'intelectual coletivo' do gramscismo: o aparelho partidário de agitação e propaganda, onde a distribuição de frases feitas, de preconceitos e de cacoetes mentais faz as vezes de vida intelectual. Daí o título deste livro", explica no Prólogo (CARVALHO, 1997, p. 43).
}

Diante da evidência da presença recorrente de Gramsci nas interpretações que fazem esses 
intelectuais sobre a história recente do país e sobre a conjuntura presente, a busca das causas do fortalecimento crescente da inserção do grupo na esfera pública nacional, enquanto fenômeno social, deve passar, necessariamente, por um esforço sistemático de compreensão da relação estabelecida por esses personagens com o pensador sardo, morto em 1933 nos cárceres da Itália Fascista.

Pois ao mobilizarem a teoria gramsciana para construir um quadro interpretativo próprio onde os inimigos de esquerda teriam logrado, ao longo das últimas quatro décadas, conquistar hegemonia no plano político e cultural nacional, os intelectuais de direita passam a se enxergar - dentro dessa leitura particular da realidade - como vítimas marginalizadas pelo establishment intelectual nacional. Munidos dessa autoimagem de resistência, o grupo afirma ter sido forçado pelas circunstâncias a atuar em sentido "contra-hegemônico", na defesa do livre mercado capitalista e de pautas comportamentais conservadoras.

Aqui não se pretende testar as conexões entre essa interpretação particular e a realidade social concreta, mas partimos do pressuposto de que tal narrativa, ainda que fantasiosa, seja elemento-chave para a compreensão das estratégias discursivas adotadas pelos intelectuais em questão. Daí a justificativa da realização do presente artigo, enquanto esforço inicial, ponto de partida do desafio de trazer à tona a influência, nem sempre declarada, exercida por Gramsci na forma como os intelectuais da "nova direita" não apenas interpretam a realidade social e formulam seus argumentos, como também intervém no debate público, fazendo uso de diferentes meios de comunicações e variados estilos discursivos para disputar hegemonia na sociedade brasileira.

Sendo o fenômeno do fortalecimento recente dos intelectuais de direita interpretado através dessa chave analítica muitas vezes por eles próprios. "A hegemonia cultural de esquerda começara a estilhaçar em 1996, e o processo era irreversível" (2017, p. 51), declarou o doutor em Antropologia Social Flávio Gordon no recente best-seller A Corrupçãoda Inteligência:Intelectuais e Poder no Brasil, tomando como marco desse processo de dimensões históricas o lançamento de O Imbecil Coletivo: Atualidades Inculturais Brasileiras (1996), de Olavo de Carvalho, mestre com quem aprendera a ter "altivez intelectual" e que teria o mérito de ter feito, em A Nova era e a Revolução Cultural (1994), "o primeiro exame crítico da obra de Antonio Gramsci - depois de décadas de puro deslumbramento e tietagem" (GORDON, 2017, p. 85).

Esse primeiro exame crítico, contudo, não dispensou ofensas pessoais e desqualificações absolutas de Gramsci como pensador. Podendo parecer surpreendente ao leitor que Olavo tenha dedicado metade de um livro ao

"profeta da imbecilidade, o guia de hordas de imbecis para quem a verdade é a mentira e a mentira a verdade. Somente um outro imbecil como Mussolini podia considerá-lo uma inteligência perigosa. O perigo que há nela é o da malícia que obscurece, não o da inteligência que clareia; e a malícia é a contrafação simiesca da inteligência" (CARVALHO, 1994, p. 55).

Se para "quem quer que pense com a própria cabeça, as teorias de Gramsci não apresentam o menor interesse" (CARVALHO, 1994, p. 56), não fica muito claro a quem texto é dirigido. Mas Olavo é ao menos mais explícito na sua interpretação da teoria gramsciana, situando-a na história da filosofia ocidental - quadro retórico utilizado na maioria de suas intervenções - como reedição má atualizada das velhas escolas céticas gregas.

Olavo chega a falar em "psicopatologia" e "delírio de interpretação", mas ao final termina por negar a Gramsci a condição de doente mental que atribui a Jean-Jacques Rousseau, classificando o sardo simplesmente como "um homem hostil à verdade onde quer que ela aparecesse e sob qualquer forma que se apresentasse", comprometido de

\footnotetext{
"maneira essencial e visceral com a paixão - talvez a mais violenta e arrebatadora de quantas existem de trocar o verdadeiro pelo verossímil, de preferir
} 
ao autêntico o simulacro, até o ponto de fazer da simulação e da pantomima o princípio mesmo da História e do mundo" (CARVALHO, 1999).

A consequência da suposta negação de Gramsci em relação a qualquer conhecimento objetivo seria a redução da atividade intelectual à propaganda e à manipulação das consciências. Sendo impossível à mente humana descrever qualquer forma de real, a única finalidade dos esforços culturais e científicos seriam expressar desejos subjetivos de entidades coletivas voltadas à assimilação total da sociedade através da "criação" de verdades universais falsas, após rejeição das verdades universais verdadeiras.

Livre da constrição dos fatos e do compromisso com o conhecimento efetivo da realidade, Gramsci teria se lançado num projeto de ambições ilimitadas, voltado ao domínio absoluto da realidade social através de ação febril, torpe e sorrateira, caracterizada pela sedução, indução e manipulação de consciências.

"A falsidade da doutrina gramsciana não nasce de simples erros ou preconceitos parciais sobre um fundo de autêntico espírito filosófico e amor à verdade. Ela decorre de um desvio fatal do espírito, de uma opção tenaz pelo engano, que vicia todo o conjunto do seu pensamento. Enquanto a maioria dos filósofos vislumbra alguma verdade essencial e depois tira dela algumas consequências inaceitáveis, Gramsci se compromete desde o início com um erro essencial que contamina e deforma com uma perspectiva falsa até mesmo as inúmeras verdades de detalhe que ele apreende sobre mil e um assuntos" (CARVALHO, 1999).

O objetivo do relativismo absoluto de Gramsci seria empreender um projeto de lavagem cerebral em larga escala que varresse do mapa, de uma só vez, toda a tradição do pensamento ocidental e com ela a distinção entre "verdade" e "falsidade". $\mathrm{O}$ que o colocaria em confronto com o próprio Marx, que se enxergava como herdeiro de grandes tradições filosóficas, em seu esforço de erigir explicação científica do processo histórico.

Da influência do pragmatismo de Antonio
Labriola, Gramsci teria herdado, na visão de Olavo, um conceito de verdade meramente instrumental, julgado não de acordo com os fatos, e sim a partir da mera "adequação" das ideias a um determinado estado da luta social. Aqui, "verdade" não é um estado objetivo, mas o que pode ter aplicação útil e eficaz numa situação dada.

Enxertando pragmatismo no marxismo, Labriola e Gramsci teriam proposto que se jogasse no lixo o conceito de verdade: na nova cosmovisão, toda atividade intelectual não deveria buscar mais o conhecimento objetivo, apenas a mera "adequação" das ideias a um determinado estado da luta social.

Diante de tamanha desonestidade ou "corrupção" intelectual - para adotar palavra utilizada por seu discípulo Gordon para descrever a intelligentsia brasileira influenciada por Gramsci (2017) - Olavo não poderia nutrir nenhum tipo de apresso pelo pensador sardo, justificando o tom agressivo: "se há algo que Gramsci não me inspira de maneira alguma, é respeito. Pode me inspirar espanto, repugnância, piedade, até mesmo hilaridade, embora seja pecado rir da desgraça alheia. Respeito, não" (CARVALHO, 1999).

Deixando de lado os sentimentos e voltando à análise das ideias, a interpretação de Olavo não deixa de chamar atenção pela radicalidade, reduzindo a fórmulas simples uma obra vastíssima, fragmentária e multitemática - por isso de difícil acesso, como o próprio reconhece (CARVALHO, 1994, p. 67) -, escrita sem pretensões de sistematização e sem compromisso com o leitor por um prisioneiro que não voltaria a experimentar liberdade.

Por não ser marxista, é natural e legítimo que Olavo questione a análise dos fatos objetivos empreendida por Gramsci como verdadeira, mas a acusação de que o sardo seria um relativista absoluto, cujo subjetivismo pragmático e amoral entraria em confronto com o pensamento de Marx, dificilmente resiste a uma incursão atenta aos Cadernos do Cárcere, até porque o próprio Olavo se contradiz mais afrente no livro, ao criticá-lo por seu economicismo: "Gramsci 
revela aqui toda a mesquinhez da sua concepção do mundo, onde a economia é não só o motor da História, mas o limite final do horizonte humano" (CARVALHO, 1994, p. 74).

Acusado por Olavo de ter sido um manipulador de consciências inescrupuloso, Gramsci também é atacado pelo autor de esquerda Perry Anderson (1976) como um pensador confuso que teria se voltado por completo às disputas superestruturais, deixando as relações sociais concretas de lado. Em comum, os ataques compartilham a tese do afastamento de Gramsci em relação a Marx, mas vale ressaltar que ambas interpretações tendem a desconsiderar o contexto histórico e biográfico em que suas teorizações foram formuladas. Sendo a "aversão a qualquer tipo de contextualismo", criticado por seu viés relativista, uma característica comum das formulações da "nova direita" identificada por Chaloub e Perlatto (2016, p. 33).

Esse foco nos temas superestruturais, ao invés de negar, também poderiam ser interpretados como aprofundamento da filosofia marxista. É o que faz, por exemplo, Louis Althusser no clássico Por Marx (1969). Pois o que Gramsci quer ao reivindicar a tradição do idealismo alemão não é substituir o primado economicista da estrutura - predominante no movimento comunista internacional de seu tempo - pelo primado da superestrutura, mas, sim, reestabelecer um equilíbrio analítico sobre as relações, sempre tensas e dinâmicas, entre os dois planos indissociáveis da realidade social.

Gramsci não chega a desenvolver pensamento econômico próprio, e suas interpelações do real vão se manter, durante toda vida, ancoradas na teoria marxista, girando sobretudo em torno do Prefácio à Crítica da Economia Política de 1859. Em suas Notas Sobre Maquiavel, por exemplo, escritas no cárcere fascista, entre 1932 e 1934, apenas três anos antes de morrer, Gramsci afirma:

"É o problema das relações entre estrutura e superestrutura que deve ser posto com exatidão e resolvido para que se possa chegar a uma justa análise das forças que atuam na história de um determinado período e determinar a relação entre elas. É necessário mover-se no âmbito de dois princípios: 1) o de que nenhuma sociedade se põe tarefas para cuja solução ainda não existam as condições necessárias e suficientes, ou que pelo menos não estejam em via de aparecer e se desenvolver; 2) e o de que nenhuma sociedade se dissolve e pode ser substituída antes que se tenham desenvolvido todas as formas de vida implícitas em suas relações" (2012, p.36).

Gramsci devolve protagonismo ao ator social sem, contudo, libertá-lo totalmente das determinações econômicas. A potência do indivíduo emerge não de seu descolamento das estruturas, mas de sua capacidade de colocar seu intelecto, sustentado pelo acúmulo do conhecimento humano, a serviço do desafio de se extrair sentido da multidão de fatos, compreendendo os movimentos tectônicos vindos da esfera econômica e suas reverberações sociais com o objetivo de romper de forma radical com lógica capitalista, estabelecendo, assim, um novo equilíbrio social em que prevaleça a classe trabalhadora.

Mesmo que reconhecesse a análise concreta das relações de força empreendida por Gramsci como verdadeira, Olavo continuaria rejeitando sua motivação como meramente instrumental, numa acusação que dificilmente seria refutada pelos defensores do sardo. Pois, para Gramsci, análises de relação de força não podem ser fins em si mesmos - salvo exceção de redação de textos sobre a história do passado -, só adquirindo algum significado se servirem "para justificar uma atividade prática, uma iniciativa de vontade" (2012, p. 46).

Homem de ação e dirigente do Partido Comunista Italiano, Gramsci herda essa concepção radicalmente realista e politizada da sociedade de uma leitura própria de Maquiavel, interpretando-o como pensador progressista, homem à frente de seu tempo, que não apenas teria fundado a moderna Ciência Política, cuidando ainda de disseminar seu conhecimento à população, com objetivo último de democratizar o acesso ao poder, até então justificado por ordem divina. Essa interpretação, todavia, é rejeitada 
radicalmente por Olavo, que só enxerga nos ensinamentos do autor de $O$ Príncipe o estímulo à mentira, trapaça, extorsão, roubo e homicídio, como táticas inescrupulosas voltadas ao objetivo exclusivo de "concentrar em si todo o poder, derrubando pelo caminho leis, instituições e valores" (CARVALHO, 2013, p. 472).

Ainda que nem todos compartilhem a rejeição radical de Olavo a Maquiavel - até porque influentes pensadores conservadores como Leo Strauss reconhecem no autor de $O$ Príncipe um dos fundadores da moderna filosofia política (MENDES, 2015, .63), os intelectuais de direita aqui analisados costumam enxergar na aplicação prática da leitura de Maquiavel feia por Gramsci a origem de um processo de empobrecimento da cultura e da produção do conhecimento em geral, reduzidos a simples instrumentos das disputas políticas.

\footnotetext{
"Gramsci forneceu aos comunistas o salvoconduto de que precisavam para se lançar à missão de instrumentalizar toda atividade intelectual e artística. É a tese da locupletação geral. Uma vez aceita a premissa de que a cultura trai sempre, e necessariamente, um projeto de poder - não há arte ou ciência 'neutras', como costumam alegar os gramscianos -, a completa politização da vida cultural, conquanto feita em nome da 'classe proletária, estará justificada. Trata-se de boa e velha desculpa do 'todo mundo faz', com a qual o leitor brasileiro certamente está familiarizado" (GORDON, 2017, p. 93)
}

Pela leitura da "nova direita", a teoria gramsciana representaria a atualização das velhas estratégias comunistas, adaptadas a um novo momento histórico onde o "grosso amálgama de retórica e força bruta" da tradição comunista ocidental teria sido forçado a dar lugar, sobretudo a partir da década de 1960, a uma "delicada orquestração de influências sutis", na visão de Olavo, "mais perigosa, a longo prazo, do que toda a artilharia do Exército Vermelho" (CARVALHO, 1994, p. 47).

O grande mérito de Gramsci - reconhece o grupo - teria sido perceber, ainda muito cedo, as particularidades da Revolução Russa, apontando a dificuldade prática de se aplicar o modelo marxista-leninista ortodoxo, de assalto ao poder estatal seguido do estabelecimento de ditadura da vanguarda organizada no partido revolucionário, a países capitalistas mais desenvolvidos.

Em sociedades complexas, o grupo dominante não poderia exercer poder apenas através da coerção, devendo buscar também o consentimento de outros grupos sociais para exercer a direção da sociedade. O que significa buscar a expansão máxima do grupo sobre todas as trincheiras que compõem uma complexa sociedade civil, mas apresentando esse movimento como

\begin{abstract}
“a força motriz de uma expansão universal, de um desenvolvimento de todas as energias 'nacionais', isto é, o grupo dominante é coordenado com os interesses gerais dos grupos subordinados e a vida estatal é concebida como uma contínua formação e superação de equilíbrios instáveis (no âmbito da lei) entre os interesses do grupo fundamental e os interesses dos grupos subordinados, equilíbrios em que os interesses do grupo dominante prevalecem, mas até um determinado ponto, ou seja, não até o estreito interesse econômico-corporativo" (GRAMSCI, 2012, p. 42).
\end{abstract}

Pela formulação de Gramsci, o exercício de hegemonia exige necessariamente que sejam levados em conta os interesses e as tendências dos grupos sobre os quais a hegemonia será exercida, formando certo equilíbrio de compromisso, sempre instável. Na prática, isso significa que o grupo dirigente deve fazer algum tipo de sacrifício de ordem econômico-corporativa; evidentemente dentro de limites estreitos que não comprometam seu domínio sobre o núcleo decisivo da atividade econômica.

Portanto, quando Gramsci afirma que um grupo historicamente avançado deve ser dirigente, ou seja, conquistar hegemonia, antes de assumir o controle do aparelho estatal - sendo esse movimento antecipado necessário para garantir a viabilidade do próprio exercício do poder, uma vez que a simples coerção já não pode 
bastar - sua concepção de hegemonia nutrida do realismo de Maquiavel e da análise da história concreta do Risorgimento Italiano pressupõe não apenas o reconhecimento dos interesses particulares de diferentes grupos sociais, como ainda a necessidade da classe hegemônica de fazer concessões reais a esses grupos em soluções de compromissos marcados pela instabilidade.

Esse elemento da teoria gramsciana, caracterizado por seus defensores como democrático, ou é completamente ignorado pelos intelectuais de direita brasileiros ou denunciado como meramente tático, uma vez que a democracia seria um valor absolutamente incompatível com as ideologias de esquerda.

Para Rodrigo Constantino, o que torna a estratégia gramsciana tão perigosa é exatamente o fato de trabalhar por apodrecer os pilares democráticos de dentro da própria democracia, subvertendo seus valores e corroendo seus fundamentos.

“Os gramscistas falam em 'democracia radical' ou 'radicalismo democrático' para se referir a tal modelo. Essa deturpação da ideia de democracia é útil para a causa socialista, pois permite que se fale em 'socialismo democrático', distanciando-se, no imaginário popular, do regime ditatorial adotado na União Soviética. Isso garante o respaldo de legalidade, evitando assim eventuais resistências e reações da sociedade" (CONSTANTINO, 2013, p. 95).

$\mathrm{O}$ acolhimento da teoria gramsciana teria sido a forma encontrada pela esquerda mundial de se renovar, respondendo, de uma só vez, a duas demandas fundamentais: distanciar-se do legado do stalinismo soviético derrotado e apresentar estratégias de ação revolucionária adequadas à realidade das democracias ocidentais, diante do fracasso da ideia luta armada, reanimada durante curto período pelo sucesso improvável da Revolução Cubana e pela disseminação das teorias de Régis Débray e Che Guevara.

A partir, sobretudo, da década de 1970, a esquerda mundial teria levado suas armas ao mundo das ideias, lançando-se numa longa guerra cultural destinada a difundir seus valores através da ocupação paulatina dos variados aparelhos privados de hegemonia, como universidades, escolas, jornais, igrejas, associações de classe, e outras trincheiras da sociedade civil tomada em sentido amplo.

Chegamos aqui a um ponto de separação em relação às interpretações favoráveis à teoria gramsciana. Enquanto estas costumam enxergar esse processo como uma disputa aberta, pacífica e democrática pelo poder, intelectuais da "nova direita" continuam a disseminar a leitura elaborada por Olavo de Carvalho no início dos anos 1990, que atribui à estratégia gramsciana caráter sorrateiro e manipulador, destinado a fazer outras classes aceitarem o domínio comunista sem ter consciência do processo.

A interpretação de Olavo ignora as concessões, acordos e reconhecimento dos interesses particulares dos diferentes grupos sociais presentes nas teorizações sobre o papel dos diferentes estratos de intelectuais nas disputas por hegemonia - extraída da análise empírica da Questão Meridional e do processo do Risorgimento Italiano -, atribuindo poder de manipulação ao pensamento de Gramsci, comparado textualmente à programação neurolinguística (CARVALHO, 1994, p. 47).

Longe de ser uma teoria aplicável à ação política legítima, a formulação gramsciana teria como objetivo disseminar mutações psicológicas de imensa profundidade através da mobilização, impensável à plena luz do dia, de

\footnotetext{
"uma pluralidade de canais de atuação informais e aparentemente desligados de toda política, através dos quais se possa ir injetando imperceptivelmente na mentalidade popular toda uma gama de novos sentimentos, de novas reações, de novas palavras, de novos hábitos, que aos poucos vá mudando de direção o eixo da conduta" (CARVALHO, 1994, p. 53).
}

O "gramscismo" seria como um vírus altamente contagioso, capaz de se propagar de forma invisível e silenciosa "por mero contágio de modas e cacoetes mentais", nas palavras de Olavo 
(1994, p. 62). Sendo a tese da epidemia vermelha quase unanimidade entre os intelectuais da "nova direita".

Em A Corrupção da Inteligência, por exemplo, Flávio Gordon afirma que a esquerda é tão "culturalmente hegemônica no Brasil que grande parte dos intelectuais públicos, quer formadores, quer difusores de opinião, é de esquerda sem nem mesmo saber disso" (2017, p. 219).

Argumento repetido por Reinaldo Azevedo de maneira ainda mais enfática: "é possível ser, digamos, "gramsciado" sem jamais ter lido Gramsci. Aliás, o "gramsciado-modelo não sabe que foi vítima de um gramsciano, hehe. É um perfeito idiota. Isso é parte da teoria" (2008).

Durante edição do programa Painel do canal de TV por assinatura GloboNews sobre "direita e esquerda" exibido em 2012, o apresentador William Waack perguntou aos entrevistados: “Torna-se impossível uma discussão dessas porque de fato boa parte da sociedade brasileira não está interessada na discussão de valores no sentido cultural amplo ou porque de fato esse monopólio gramsciniano tá de tal forma estabelecido que não há mais espaço?"

"Eu me inclino para a segunda hipótese" foi a resposta do sociólogo Bolívar Lamounier. Mesma linha seguida pelo filósofo Luiz Felipe Pondé, sentado na cadeira ao lado: "Eu tenho uma sensação de que o Brasil marcha lentamente para um certo consenso esquerdizante gramsciano" (2013).

Dentre as falas acima, a única que destoa é a de Pondé. Pois na visão dos demais intelectuais da "nova direita", a hegemonia gramsciana na vida cultural nacional não é um risco futuro, mas uma realidade há anos sedimentada, tendo sido denunciada pela primeira vez por Olavo de Carvalho, ainda no início década de 1990.

As primeiras traduções dos escritos de Gramsci chegaram ao Brasil no final da década de 1960, repercutindo, no primeiro momento, num círculo restrito de intelectuais e professores de Ciências Sociais ligados, sobretudo, à USP. A difusão de seu pensamento e, portanto, o processo de conquista de hegemonia na vida intelectual nacional só seria impulsionado na década seguinte. Não apesar, mas "graças" à ditadura militar, segundo afirma a narrativa dos intelectuais de direita.

A falta de visão do regime teria levado os militares a focarem exclusivamente na repressão à luta armada, permitindo e, num certo sentido, até estimulando a migração da esquerda para a atuação em universidades, jornais, editoras e outras associações civis. Movimento visto como positivo pelos homens de farda, por canalizar as energias da oposição na direção de ações pacificas, aparentemente inofensivas.

Em pouco tempo, a esquerda teria assumido controle de jornais e editoras, marginalizando intelectuais de direita de maneira progressiva, até excluí-los de uma vez todas. Tudo com a conivência da ditadura, cujo aparato de censura, de tão amador, seria motivo de piada, segundo Gordon (2017).

$\mathrm{O}$ autor afirma ainda que entre as décadas de 1950 e 1970 havia se dado algo como um "casamento de conveniência" entre jornalistas ligados ao PCB e os donos dos grandes jornais. Tendo os comunistas desempenhado papel importante na modernização do jornalismo brasileiro em troca do controle das redações, que seriam utilizadas "para de maneira tão discreta quanto possível, influenciar a opinião pública em favor de seu projeto político-ideológico" (2017, p. 166).

Sendo a própria Rede Globo interpretada, nessa chave, como um dos mais poderosos aparelhos privados de hegemonia utilizado pelos comunistas para difundir suas ideias através das telenovelas e outros formatos dramatúrgicos escritos por militantes como Vianinha, Dias Gomes e Janete Clair.

Segundo a formulação de Olavo, retomada e desenvolvida posteriormente por Gordon, o general Golbery do Couto e Silva teria sido diretamente responsável pelo processo, ao promover a abertura gradual do regime de maneira que entregasse a cultura de mão beijada nas mãos dos intelectuais de esquerda - agora munidos do nefasto arsenal teórico gramsciano - como forma de evitar que a sociedade brasileira se convertesse numa perigosa "panela de pressão" 
prestes a explodir, segundo metáfora utilizada pelo principal ideólogo do regime em palestra proferida, em julho de 1980, na Escola Superior de Guerra (GORDON, 2017, p. 238).

Por desconhecer Gramsci e não conseguir imaginar ações esquerdistas que não fossem de natureza insurrecional leninista, Golbery não teria sido capaz, segundo tal interpretação, de perceber o alcance que a ocupação esquerdista dos espaços culturais teria no futuro, tomando-a como inofensiva. Quando os militares finalmente devolveram o poder aos civis na segunda metade da década de 1980, era tarde demais: a esquerda brasileira já havia assimilado as lições do mestre, abandonando o radicalismo infantil, as fantasias armadas e as pretensões de pureza ideológica para se dedicar a arte de "aliciar" e "comprometer", mergulhando de uma vez por todas na "zona mais profunda da sabotagem psicológica”.

“Com Gramsci ela aprendeu que uma revolução da mente deve preceder a revolução política; que é mais importante solapar as bases morais e culturais do adversário do que ganhar votos; que um colaborador inconsciente e sem compromisso, de cujas ações o partido jamais possa ser responsabilizado, vale mais que mil militantes inscritos. Com Gramsci ela aprendeu uma estratégia tão vasta em sua abrangência, tão sutil em seus meios, tão complexa e quase contraditória em sua pluralidade simultânea de canais de ação, que é praticamente impossível o adversário mesmo não acabar colaborando com ela de algum modo, tecendo, como profetizou Lênin, a corda com que será enforcado" (CARVALHO, 1994, p. 15).

\section{PT como encarnação brasileira do "moderno príncipe" de Gramsci}

Essa centralidade na vida cultural brasileira atribuída a Gramsci pelos intelectuais de direita contemporâneos encontra questionamento na obra de Roberto Schwarz, que em Cultura e Política no Brasil: 1964-1969 (1978) argumenta que o processo de conquista de hegemonia cultural pela esquerda havia começado ainda no governo Jango, portanto antes da difusão da obra do comunista sardo entre nós.

Além de questionável do ponto de vista histórico, essa interpretação negativa que atribui poder descomunal à aplicação da teoria gramsciana à realidade brasileira contemporânea não vai ignorar a necessidade - extraída por Gramsci de Maquiavel - de algum elemento capaz de dar unidade à luta pela construção hegemônica, dirigindo e organizando trabalho educativo no sentido do amadurecimento da consciência de classe do proletariado.

Só que quatro séculos haviam se passado desde a publicação de $O$ Príncipe, e diante do contexto social e do grau de desenvolvimento que haviam alcançado as forças produtivas já em seu tempo, não seria possível a Gramsci enxergar numa única pessoa o condottiero com as qualidades necessárias à tarefa.

"O moderno príncipe, o mito-príncipe não pode ser uma pessoa real, um indivíduo concreto, só pode ser um organismo; um elemento complexo de sociedade no qual já tenha tido início a concretização de uma vontade coletiva reconhecida e afirmada parcialmente na ação. Este organismo já está dado pelo desenvolvimento histórico e é o partido político, a primeira célula na qual se sintetizam germes de vontade coletiva que tendem a se tornar universais e totais" (GRAMSCI, 2012, p. 16).

Seria o partido político revolucionário enquanto expressão orgânica de uma classe social destinada, pelo desenvolvimento das forças produtivas, ao exercício de hegemonia - um novo personagem histórico, surgido para enunciar e organizar uma reforma intelectual e moral que preparasse o terreno para um novo desenvolvimento da vontade coletiva nacionalpopular no sentido da realização de uma forma superior e total de civilização moderna (GRAMSCI, 2012, p. 15).

Nesse sentido, é necessário que o "moderno príncipe", assim como o ator de Maquiavel, mantenha o domínio das circunstâncias, voltando-se enquanto inteligência coletiva à análise ininterrupta das correlações de força, 
indispensável à execução eficiente do dever histórico. E essa ação se torna possível porque cada membro do partido pode ser considerado, à sua maneira, um intelectual, ainda que em graus distintos, pois a função de todos é essencialmente a mesma: diretiva e organizativa, ou seja, educativa e intelectual.

No Brasil, o "moderno príncipe" teria sido encarnado pelo Partido dos Trabalhadores, visto pela "nova direita" como um partido de intelectuais por excelência, ou a materialização do intelectual coletivo gramsciano, ridicularizado por Olavo no livro de 1996.

Através dessa chave, os anos de alta popularidade do governo Lula são lidos como um momento excepcional na história do partido, fruto da expansão e universalização de antigas práticas assistencialistas, sendo a ideia de proximidade entre o PT e as massas populares mera construção mitopoiética elaborada por sua intelligentsia, efêmera demais para ser levada a sério do ponto de vista histórico. Com a crise do governo Dilma, o PT teria voltado à sua condição original de partido de intelectuais, uma vez que o próprio movimento sindical de onde surgiu Lula teria servido mais como expressão simbólica do ideário propagado do que como grupo efetivamente dirigente. Segundo Gordon, o "PT sempre foi um partido gramsciano por excelência" (2017, p. 313).

Enquanto encarnação quase perfeita do moderno príncipe, o PT teria se mostrado eficiente na guerra de posição travada desde a década de 1970 contra um inimigo em desvantagem por - ignorando Gramsci - desconhecer as próprias regras do jogo. Nessa leitura, o partido teria capitaneado o processo de conquista de hegemonia na sociedade civil, ocupando ou "aparelhando" - termo mais utilizado pela direita - jornais, editoras, universidades, governos, câmaras legislativas, tribunais, além dezenas de entidades de classe e organizações da sociedade civil, como a UNE, a OAB e a CNBB, entre outras.

Entre as evidências empíricas do caráter gramsciano do PT estaria na presença em seus quadros de seguidores declarados do sardo, como Carlos Nelson Coutinho, Marco Aurélio
Nogueira e Francisco Weffort, que teriam sido capazes de se sobrepor à pluralidade de tradições que compunham o partido - desde o sindicalismo do $\mathrm{ABC}$ à esquerda católica, passando pelos trotskistas que deixariam o PT no futuro para fundar o PSOL.

Outra prova comumente utilizada pela direita é o vídeo exibido no III Congresso Nacional do partido, de 2008, em que se afirma que "os trabalhadores precisam transformar-se em classe hegemônica e dominante no poder de Estado" e que "não basta chegar ao governo para mudar a sociedade. É preciso mudar a sociedade para chegar ao governo" (AZEVEDO, 2008, p. 22).

Desmascarando o PT como encarnação brasileira do moderno príncipe, a nova direita acredita expor a verdadeira face do partido, totalitária. Nesse sentido, a submissão de Lula ao sistema financeiro assinada na Carta ao Povo Brasileiro, de 2002, e a aliança com o grande capital não seriam sinais de moderação ou de adesão do partido à economia de mercado, mas simples adaptação discursiva - circunstancial e tática -, transformando em "virtuoso" o que era antes tido como "criminoso". Pois seu julgamento deve ser submetido não a imperativos morais transcendentes, mas somente aos interesses de expansão do próprio partido.

“O Moderno Príncipe, desenvolvendo-se, subverte todo o sistema de relações intelectuais e morais, uma vez que seu desenvolvimento significa, de fato, que todo ato é concebido como útil ou prejudicial, como virtuoso ou criminoso, somente na medida em que tem como ponto de referência o próprio Moderno Príncipe e serve ou para aumentar seu poder ou para opor-se a ele. O Príncipe toma o lugar, nas consciências, da divindade ou do imperativo categórico, torna-se a base de um laicismo moderno e de uma completa laicização de toda a vida e de todas as relações de costume" (GRAMSCI, 2012, p. 19).

É nessa passagem das notas sobre Maquiavel, citada de forma recorrente em seus textos, que os intelectuais da "nova direita" acreditam encontrar a prova definitiva e irrefutável do 
caráter "totalitário" do "teórico da ditadura perfeita", como Gramsci foi chamado pelo escritor peruano e Nobel de Literatura Mario Vargas Llosa (AZEVEDO, 2007).

Segundo Reinaldo Azevedo (2007), nessa passagem Gramsci teria ido mais fundo na defesa do totalitarismo - conceito aqui compreendido como ideologia de controle ilimitado de todos os aspectos da vida pública ou privada - do que qualquer teórico anterior, incluindo seus inimigos fascistas, pois pressupõe o aniquilamento de qualquer sistema moral, ao definir o que é virtuoso ou criminoso de acordo com as necessidades do partido. Seu objetivo, nesse sentido, seria a completa destruição da autonomia de pensamento do indivíduo.

Ao tomar essa passagem de forma isolada e descontextualizada, a interpretação de Azevedo, compartilhada por outros intelectuais de direita, também poderia ser lida por defensores de Gramsci como tentativa de superdimensionar tendências totalitárias do seu pensamento, justamente por ignorar o pragmatismo ressaltado pelo próprio Olavo - e o caráter dialético de suas formulações. Uma vez que a presença de Hegel é marcante nos escritos de Gramsci, penetrando não somente pela esquerda, através de Marx, mas vindo também da direita, via influência exercida em sua juventude pela filosofia de Benedetto Croce.

Dessa forma, uma leitura atenta à dialética e ao realismo de Gramsci poderia também interpretar o projeto totalitário de transformar o partido, enquanto intelectual coletivo, em "divindade" ou "imperativo categórico" como utopia destinada a motivar a ação histórica concreta do proletariado. Ação que deveria ser, segundo a radicalidade dialética de Gramsci, integral e enérgica em ambas as classes sociais.

A submissão total de uma parte sobre a outra, denunciada pela direita como o projeto imediato do "gramscianismo", seria, nesse sentido, uma impossibilidade do ponto de vista prático, devendo a vitória futura do proletariado sonhada por Gramsci assumir face impossível de ser delineada no tempo presente. Só podendo ser pensada, nesse sentido, como alguma forma de síntese dialética favorável aos trabalhadores, resultado de um devir histórico dinâmico em que "cada membro da oposição dialética deve procurar ser integralmente ele mesmo", lançando na luta de classes “todos os seus 'recursos' políticos e morais", pois "só assim se consegue uma superação real" (GRAMSCI, 2011, p. 318).

Essa possibilidade de interpretação favorável ao sardo, contudo, é refutada por completo pela intelectualidade de direita, sobrando apenas a ideia da contaminação epidêmica do vírus totalitário gramsciano, disseminado, em território brasileiro, pelo PT,

\begin{abstract}
"partido manipulador e golpista, capaz de conduzir o país às vias fraudulentas da 'revolução passiva' gramsciana, usando para isso dos meios mais covardes e ilícitos - a espionagem política, a chantagem psicológica, a prostituição da cultura, o boicote a medidas saneadoras, a agitação histérica que apela aos sentimentos mais baixos da população" (CARVALHO, 1994, p. 16).
\end{abstract}

Por isso que o ódio ao Partido dos Trabalhadores - identificado por Chaloub e Perlatto como elemento que une os intelectuais da "nova direita" (2016) - não pode ser compreendido de forma verdadeiramente profunda sem levar em consideração Antonio Gramsci. Pois a leitura que enxerga o PT como moderno príncipe obcecado pela a implementação do totalitarismo está intimamente ligada à ideia de que a simples presença do partido no poderéirremediavelmente incompatível com a democracia. Como afirma Reinaldo Azevedo: "tudo o que é bom para o PT é ruim para o Brasil.” (2008, p. 9).

\section{Considerações finais}

O tom agressivo deve ser entendido no contexto da interpretação da história recente do país e da leitura que esses intelectuais fazem da conjuntura político e social contemporânea, onde a intelectualidade de esquerda teria conquistado hegemonia avassaladora na esfera cultural. Em 
cenário tão alarmante, a perspectiva de que o PT possa assumir o controle absoluto da sociedade surge como risco concreto. Se isso ainda não aconteceu, foi graças, entre outros motivos, à ação heroica desse grupo formado por intelectuais que resistiram ao boicote de jornais, revistas e editoras e às tentativas de silenciamento impostas pelos esquerdistas, para continuarem denunciando $\mathrm{e}$ se opondo à marcha veloz da sociedade brasileira rumo à implantação definitiva da ditadura de esquerda.

Não podendo essa autoimagem compartilhada pelos intelectuais da "nova direita" ser compreendida sem levar em consideração a onipresença fantasmagórica e fluída do grande inimigo em comum: Antonio Gramsci. Foi o que se buscou explicitar ao longo deste artigo através da análise dos textos e das intervenções públicas destes personagens.

Demonstrada a influência de Gramsci, uma hipótese emerge como consequência lógica: se a esquerda - munida do arsenal teórico do comunista sardo - tornou-se hegemônica no mundo das ideias brasileiro, resta aos poucos intelectuais de direita que conseguiram resistir contra-atacar com as mesmas armas, usando os mais variados meios de comunicação para disseminar suas ideias na esfera pública. Podendo a força desses intelectuais nas redes sociais ser interpretada como exemplo significativo nesse sentido. Olavo de Carvalho, sozinho, tem quase 400 mil seguidores no Facebook e outros $200 \mathrm{mil}$ no Twitter.

O uso dos instrumentos teóricos de Gramsci, contudo, não é assumido abertamente por nenhum desses intelectuais, ainda que alguns sejam mais explícitos em determinados momentos. No programa da GloboNews citado anteriormente, Bolivar Lamounier foi direto ao ponto: "eles fizeram uma guerra ideológica e ganharam. Nós temos que fazer a nossa" (2013).

Em artigo publicado em 2016, Luiz Felipe Pondé chegou à conclusão de que os historiadores do futuro iriam distorcer o processo de impeachment da presidenta Dilma Rousseff em favor da esquerda e que a única forma de combater essa hegemonia seria investir dinheiro na formação de jovens historiadores de direita.

“A única saída é se as forças econômicas produtivas que acreditam na opção liberal financiarem jovens dispostos a produzir uma teoria e uma historiografia do Brasil que rompa com a matriz marxista, absolutamente hegemônica entre nós. Institutos liberais devem pagar jovens para que eles dediquem suas vidas a pensar o país. Sem isso, nada feito" (PONDÉ, 2016).

Ainda que Gramsci não tenha sido citado diretamente em nenhum momento do texto, o que o filosofo propõe é que o empresariado brasileiro financie a formação de novos quadros de intelectuais de direita, capazes de disputar hegemonia no universo cultural em favor do livre mercado e dos valores conservadores. Seria esta, na sua visão, a única maneira de reverter a predominância da intelectualidade de esquerda no país.

Por não ser assumida, a hipótese de que os intelectuais de direita fazem uso das ferramentas teóricas gramscianas para disputar hegemonia ainda carece de análise mais profunda, emergindo nesse artigo como apontamento para reflexões futuras.

O objetivo aqui foi propor uma discussão preliminar, que demonstrasse através da análise crítica das ideias, retóricas e prática política a relevância de Antonio Gramsci para se compreender como os intelectuais da direita brasileira contemporânea interpretam a realidade social e percebem sua própria inscrição na vida pública, oferecendo, nesse sentido, contribuição ao esforço coletivo de compreensão, enquanto fenômeno social, do protagonismo que esse grupo de intelectuais vêm assumido na vida pública nos últimos anos.

\section{Referências bibliográficas}

ALTHUSSER, Louis. For Marx. London: The Penguin Press, 1969.

ANDERSON, Perry. The Antinomies of Antonio 
Gramsci. London: New Left Review, 1976.

AZEVEDO, Reinaldo. Direito Achado na Rua: gramscianos, "gramsciados" e reclamações. Publicado em 26 ago. 2008. Disponível em < http://veja.abril.com.br/blog/reinaldo/direitoachado-na-rua-gramscianos-gramsciados-ereclamacoes/>. Acesso em: 29 set. 2017.

AZEVEDO, Reinaldo. O país dos Petralhas. Rio de Janeiro: Record, 2008.

AZEVEDO, Reinaldo. Gramsci, o parasita do amarelão ideológico. Publicado em 8 ago 2007. Disponível em: <http://origin.veja.abril.com. br/160507/p_100.shtml> Acesso em: 29 out. 2017.

BBC. OlavodeCarvalho, o 'parteiro' da novadireita que diz ter dado à luz flores e lacraias. Publicado em 15 dez. 2016. Disponível em: <http://www. bbc.com/portuguese/brasil-38282897> Acesso em: 29 out. 2017.

CARVALHO, Olavo de. A nova era e a revolução cultural: Fritjof Capra \& Antonio Gramsci. Rio de Janeiro: Instituto de Artes Liberais \& Stella Caymmi. 1994

CARVALHO, Olavo de. O jardim das aflições: de Epicuro à ressurreição de César - Ensaio sobre o materialismo e a religião civil. Rio de Janeiro: Topbooks, 1998.

CARVALHO, Olavo de. O imbecil coletivo: atualidades inculturais brasileiras. Rio de Janeiro: Faculdade da Cidade Editora, 1996.

CARVALHO, Olavo de. O Anti-Gramsci $\sim 1$ Apostila do Seminário de Filosofia Introdução à Filosofia pelo Método Crítico-Dialético. Publicado em 10 dez. 1999. Disponível em <http://www.olavodecarvalho.org/o-antigramsci-1/> Acesso em: 29 out. 2017.

CARVALHO, Olavo de. O Mínimo que você precisa saber para não ser um idiota. Rio de
Janeiro: Record, 2013.

CONSTANTINO, Rodrigo. Esquerda caviar: a hipocrisia dos artistas e intelectuais progressistas no Brasil e no mundo. Rio de Janeiro: Record, 2013.

CHALOUB, Jorge. \& PERLATTO, Fernando. 2016. A Nova Direita Brasileira: Ideias, Retórica e Prática Política. Insight Inteligência N 72; Ano XIX; Janeiro/Fevereiro/Março.

GLOBO NEWS. Painel. Publicado em 28 dez. 2013. Disponível em: <: https://www.youtube. $\mathrm{com} /$ watch?v=-BYsM3peQPw\&t=141s $>$ Acesso em: 29 out. 2017.

GORDON, Flávio. A Corrupção da Inteligência: Intelectuais e Poder no Brasil. Rio de Janeiro: Record, 2017.

GRAMSCI, Antonio. Cadernos do Cárcere, Vol 3. Rio de Janeiro: Civilização Brasileira, 2012.

GRAMSCI, Antonio. Cadernos do Cárcere, Vol 5. Rio de Janeiro: Civilização Brasileira, 2011

MEDEIROS DE FREITAS, Francisco Josué. Cultura Democrática e Esquerda Brasileira: comparando a concepção de política do PCB e do PT. V Congreso Latinoamericano de Ciencia Política. Asociación Latinoamericana de Ciencia Política. Buenos Aires, 2010.

MENDES, Elvis de Oliveira. Política e Religião no Pensamento Filosófico de Leo Strauss. Dissertação de mestrado. Recife: UFPE, 2015.

PONDÉ, Luiz Felipe. A história do Brasil do PT. Publicado em 18 abr. 2016. Disponível em: <http://www1.folha.uol.com.br/colunas/ luizfelipeponde/2016/04/1761876-a-historia-dobrasil-do-pt.shtml> Acesso em: 29 out. 2017.

SCHWARZ, R. Cultura e política no Brasil: 19641969. In: O pai de família e outros estudos. Rio de Janeiro: Paz e Terra, 1978 